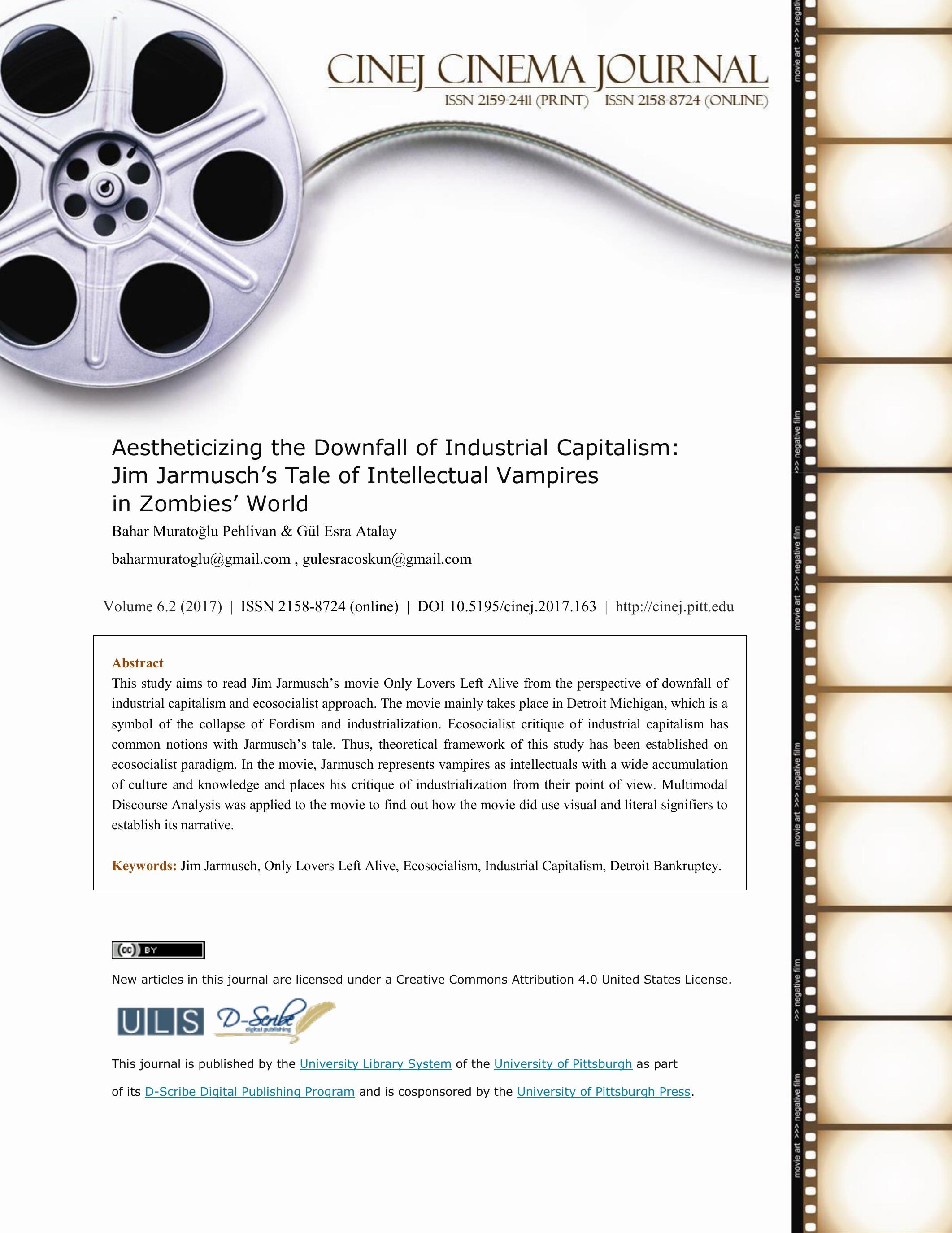




\section{Aestheticizing the Downfall of Industrial Capitalism: \\ Jim Jarmusch's Tale of Intellectual Vampires in Zombies' World}

Bahar Muratoğlu Pehlivan* \& Gül Esra Atalay ${ }^{* *}$

Where there is ruin, there is hope for treasure.

Rumi

\section{Introduction}

In the recent years there has been a booming rise in the vampire sub-genre, not only in the mainstream movie industry, but also in the independent and European cinema.

In his movie, Only Lovers Left Alive, Jim Jarmusch offers a distinctive discourse and redefines vampires as figures of intellectual bohemian bourgeois who have witnessed the entire human history and survived by means of art, literature, science and love. As an immortal vampire couple, leading figures of the movie, Adam and Eve represents the very first man and woman who had been there since the beginning, thus, have a very rich accumulation of culture, scientific and intellectual knowledge.

Abel Ferrara's 1995 movie The Addiction was the predecessor of the intellectualized vampire figures. The story was about a P.H.D candidate on Philosophy who was converted into a vampire. While Ferrara's intellectual vampire was questioning the violence within herself in an existentialist way, Jarmusch's vampires are suffering from what humankind has done to the world.

In her article on Ferrara's The Addiction, Nadine (2000, p. 227) states that "The undying appetite of the vampire finds its invisible reflection in the age of electronic consumerism where our appetite is never appeased." In Jarmusch's Only Lovers Left Alive, main trouble that the protagonists are dealing with is the mass consumerism and industrialization. However, it's not vampires but humans who are representing this never appeased appetite. Actually, vampires are represented as figures with a wide range of cultural accumulation. What is more, Alleva (2014, p. 
24) points out that the film hints that most of the well-known European and American artists have been either vampires or companions of the undead.

The movie mainly takes place in Detroit, Michigan, that is the city that symbolizes the downfall of industrial capitalism and Fordism. Detroit has been hit by the failure of the American automobile industry, and the city lost a vast amount of population and tax base. As a result, it declared bankruptcy (McDonald, 2014, p.3309).

Eisenger (2014, p. 2) likens Detroit to "a patient in extermis", who has only a few working vital functions. He adds that the city cannot govern itself and cannot serve its residents' economic interests.

While Detroit is shedding its last blood; Jarmusch positions his vampire couple in the city, to find treasure in the ruins. In the movie's atmosphere, we see two protagonists patrol around Detroit, along abandoned buildings, dark streets, evacuated houses, just as if they are sightseeing.

After the bankruptcy of Detroit in 2013, there has been much debate on the concept of ruin porn (Vultee, 2013, p. 142-144), as there were tour organizations to Detroit ruins (Slager, 2013, p. 2). However, in this movie, protagonists do not take a pornographic pleasure from the ruins, but from the collapse of the industrial capitalist system.

On the other hand, leading character of the movie, Adam, choses to live in the heart of this collapse and foresees the evacuated city's rebirth in its water, in other words in its natural sources. Indeed, Detroit's official motto which was written after the Great Fire of 1805, is much alike: "Speramus meliora; resurget cineribus (We hope for better things; it shall rise from the ashes)." (Galster, 2015, p. 19).

Commenting on the ruins of Detroit and going back to nature, Anderson (2012, p. 199) states that, ruined structures of Detroit are actively reclaimed by natures' agents. She adds that 
abandoned buildings, industrial plants etc. in Detroit are "occupied by native grasses, wildflowers, snowdrifts and wind storms". In this - close to nature- situation, competing natural forces copresent in Detroit.

Millington (2010, p. 3) claims that, although declining, Detroit is a city in the making. It will never be the same but it will rather reincarnate than die. She suggests that arising ecologies and spatiality in Detroit may lead to a new conceptualization of urban places. To understand postindustrial metropolis, ecology would be a vital point of view.

In the light of these points of views, and keeping in mind that Adam preferred to live in this city, a theoretical approach to the discourse of the film leads us to ecosocialism, which criticizes industrial capitalism in a very similar way.

Shaping the literature on ecosocialist approach, Joel Kovel (2014, p. 10) argues that the world is in the edge of a radical crisis, economically and ecologically. According to him, although these two aspects are separately treated, they are the two faces of a deeper crisis, "an estrangement from nature stemming back to the origins of civilization." Kovel claims that this will head toward a "Dark Age", which might end with the extinction of humankind.

Vital point in Kovel's (2014, p. 10) work is that he states, ecology stands for the connection between nature's elements. Humans as part of nature are connected in ecosystems with the “connections". Therefore ecological crisis should be evaluated as existential. Anyway this does not happen, as humans are alienated from nature. Kovel thinks that radical eco-politics would overcome this situation.

According to Löwy (2015, p. 2-3), Marx is against the "production for production" principle of capitalism, but neither Marx nor Engels, showed a sufficient "critical attitude toward industrial civilization, notably in its destructive relationship to the environment". And they had a “tendency to make 'development of the productive forces', the principle vector of progress". Thus, 
Marxist thought has to be renewed taking ecological sensitiveness into the consideration. Productive forces conception of Marxists has to be revised and it has to put a distance between itself and with the ideology of "linear progress and with the technological and economic paradigm of modern industrial civilization”.

Along the same line, O'Connor (1998, p.164) regards the departure point of ecological Marxism as "the contradiction between capitalist production relations and productive forces, on the other hand, and conditions of production on the other". He adds that human labor power, external nature, infrastructures are not produced capitalistically; nevertheless, capital treats them as if they are commodities.

Kovel (2007, p. 123) claims that there are some applicable innovations that may contribute to the solution of the ecological crisis, however they are ignored due to the fact that they run against the obligations of accumulation. He continues to say that science is labelled as being responsible for humanity's disengagement from nature. However this does not apply to all scientific studies. Therefore if one wants to explain this disengagement one must go back to origins of domination.

Kovel (2014, p. 17) emphasizes the "de-spiritualization", which is a result of capitalist modernity. Spirit became a commodity of culture industry, such as Disney Corporation and it is reduced to racing cars, supermodels etc. In consequence of this, human beings are spiritually confused and become incapable of ecosocialist transformation.

Betto and Löwy (2010, p. 97) discuss that transforming the unsustainable pattern of consumption of capitalism, especially its industrialized canters is a challenge. They regard the “obsessive accumulation of goods along with compulsory acquisition of pseudo-novelties imposed by fashion" as a base for capitalist consumption, which is another challenge.

Similarly, Schwartzman (2009, p. 13) talks on the concept of "entropy" and he defines it 
as disorder and loss of complexity and structure in a system. He continues to say that the ecological crisis that generate pollution and decrease biodiversity can be seen as increasing disorder, so producing entropy in the biosphere. He claims that entropy is the metaphor that must be used to find the path to recover human and natural communities by rule out capitalism, in other words the “Great Entropy Generator”.

\section{Method}

In the movie, Jarmusch creates a world full of references and messages, which can all, be analyzed individually as separate discourses. The film includes more than one contradiction, such as industrial capitalism versus genuine science, art and nature, and average men versus intellectuals. The analyses of this study will serve only to a limited dimension of the movie and will be focused on the perspective of industrial capitalism versus genuine science and art and nature. Due to the fact that the messages of the movie are represented by the audial, visual and verbal signifiers, Multimodal Discourse Analysis was applied (Machin \& Mayr, 2012).

\section{Multimodal Discourse Analysis}

RQ1: How is the contradiction between industrial capitalism and genuine science, art and nature represented?

RQ2: How are vampires vs. humans (zombies) in other words intellectuals vs. average man/woman positioned?

RQ3: How is the downfall of industrial capitalism is represented in the visual and oral discourse?

RQ4: How do these discourses function to give an ecosocialist approach, which is in opposition with mass production, progress and growth obsession of industrial capitalism? 
Discursive construction of industrial capitalism vs. genuine science, art and nature

In the movie, discursive construction of industrial capitalism vs. genuine science, art and nature has been done with metaphor, structural oppositions, personification, and attributes discursive closures.

There are several structural oppositions in the movie, one of them is as follows: Detroit was once the heart of uprising Fordist Industry. After the bankruptcy, the city became an abandoned, dark and wild place, which is in contradiction to latest capitalist and popular life style. This message is given by Adam's condescending comment on L.A, as he defines it "Zombie Central", in other words, the capital of consumerist culture.

Another structural opposition comes along when Adam and Eve visit the once glorious Michigan Theatre. Adam explains to Eve that the place was built on Henry Ford's atelier where he made his first prototype. The theatre has then turned into a car park. This is a symbolic point in Detroit's history that shows how industry regained the space and replaced the genuine art.

Contradiction between the high tech industrial goods and classic technological devices while Adam and Eve makes a long distance call is also a structural opposition. Eve uses a white iPhone and Adam answers with a cordless phone, which he attaches to his laptop and old-fashioned TV. This scene is the first point in which Adam's approach to modern technology is shown; Adam is not against the technology itself but how it is produced and consumed by today's industrial paradigm.

Same message takes place also in the scene where Adam turns his eye on the electrical cables outside the building he lives. The lights go out and two protagonists of the film, Adam and Eve are in the garden checking for network. Adam comments on the all mixed up electricity cable as he says "Fucking zombie shit. It's so antiquated. What century is this? Tesla had light bulbs 
and not even a plug-in in 1895." Here, mixed up electrical cables function as a metaphorical discourse for the mess that is caused by human beings on earth.

It's understood that Adam disconnected the electrical cables from the network and apparently he produces his own electricity using a generator he assembled. The generator receives electrical information from the atmosphere. Adam's attitude towards technology is more of a science oriented than industrial manufacturing and marketing. As an immortal vampire who has witnessed all the scientific developments, he genuinely feels desperate about the way scientists were treated and how humankind wasted the opportunity to develop a better outcome from the beautiful minds of the history.

His desperation comes out with his statement about the scientists as follows:

“Look what they've done to them. Pythagoras, slaughtered... Galileo imprisoned. Copernicus ridiculed. Poor old Newton pushed into secrecy in alchemy. Tesla, destroyed. His beautiful possibilities completely ignored. And they are still bitching about Darwin.”

Tesla was referred more than one time in the movie. The difference between his scientific imagination and the current state of modern technology represents the gap between Adam's view of science and today's industrial manufacturing.

Likewise, mass production caused by industrial capitalism leads to the loss of authenticity and value of art works and also scientific discoveries, which are standing in the movie as structural oppositions. Remembering Benjamin's classical article The Work of Art in the Age of Mechanical Reproduction, it is possible to state that Adam is against the mass production and industrialization of cultural elements, and their perishing influence on the aura of art works. His position on the issue can be found in the following examples:

Adam is a musician but he rejects the idea of his music to be found online by people and be popular. On the other hand, we learn that his music is already being downloaded and listened 
in L.A clubs, which also points to the fact that the faith of the work is not in the hands of the artist. It is not coincidental that Jarmusch chooses to mention L.A, as it is the heart of America's music and movie industry. As stated above, Adam calls the city "Zombie Central".

Another scene showing Adam's attitude against the industrial production is his comment about Yasmine Hamdan, a Lebanese singer who was performing in a nightclub in Tangier. Listening her singing in admiration, Adam expresses his wish for her not to become famous because "she is way too good for that."

Adam's passion for vintage music instruments also serves as an epitome for his rejection of mass production. For him, every single one of those instruments that he collects has a great value in which he probably finds the aura that is lost in the new age, industrially produced instruments.

In the movie, personification has also been used as a discursive closure. This choice of discourse attributed Detroit a personality similar to a patient fighting a disease, thus, taking a role as a hero in nature's fight against industrial capitalism.

Adam believes that Detroit will rise again with its water sources when the southern cities will be burning. The city that has collapsed with industry will find its way back to bloom with nature. In this sense as Jarmusch puts it, Detroit is the symbol of hope for nature with its war against industry. This hope is embodied as an attributive discourse closure in the "I Love Detroit" coffee cup that can be seen in the hospital scene, where Adam retrieves clean blood.

In the atmosphere of the movie, there are various references to 60' and 70's. Music, many musical instruments and belongings that can be heard and seen belong to this time period. This attributive discourse functions like a tie Jarmush constructs with Hippie culture of those times. Hippie generation is associated with the values of going back to nature, anti-capitalism and anti- 
war. In a way, protagonists of the film, Adam and Eve can be evaluated as modern upper class hippies.

In the scene where Adam and Eve go down to Adam's garden, Eve recognizes a type of fungi, which arrived at the wrong season. Adam explains that they appear and disappear and reappear, and he adds that "Maybe the life from the planet couldn't live without them." This is a point that shows Jarmusch's emphasis on hazardous effects of humankind on ecosystem.

\section{Discursive construction of intellectuals versus ordinary people}

Discursive construction of intellectuals versus ordinary people in the movie has been done with metaphor, individualization versus collectivization, specification, genericization, us and them division, and salience discursive closures.

In the discourse of the movie, ordinary people are collectivized. They are named as "Zombies" who are deprived from critical thinking and conscious. They are generic types of illiterate and ignorant human beings who are all led by the same urges. On the other hand, vampires, who represent the intellectuals, are shown as individual unique characters. Their identities are detailed. All the vampire figures of the movie are given with their specific personalities.

Another discursive practice that is visible in the movie is us and them division. Protagonists of the movie, Adam and Eve, and also their beloved friend Marlowe position themselves above and distant from the ordinary people. In their discourse, ordinary people are referred as "they", and this "they" are always mentioned with ignorance, indifference, and destruction and harm they caused for the planet. 
Salience is another form of discursive closure that is seen in the movie. Cultural symbols such as antique musical instruments, old books, pictures of renowned scientists and artists give the sense of the habitat of an intellectual.

Detroit, the main scene of the collapse of industrial capitalism in USA, is defined as 'Zombie City' by Phillips (2014, p. 704), a term he uses to point out the "decimated urban areas that are brought back to life by mystical means such as public policy". The leading character of the movie, Adam, refers humans as zombies. Zombie is a metaphor that represents the average, consuming oriented and lumpen people. The choice of the word "zombie" by Jarmusch is a conceptual inversion, as zombie means living dead and normally the word suits more to vampires than humans, due to the fact that vampires are physically dead. The movie points out that humankind is psychically alive but mentally dead. Humans are referred as Zombies in the sense that they consume and consume without producing and they don't appreciate genuine science art and nature, finally they are not aware of the harm that they cause to the planet.

As another deal for their dissent against zombie world, Adam, as a recognized musician, rejects to be popular, and he doesn't like the idea of his music to be downloaded via Internet. He also doesn't want to meet with his fans, who are persistently trying to reach him.

The protagonists have a deep knowledge of antique and genuine goods, due to the fact that they have an enormous experience in the World. As vampires they have witnessed a very long period of life on earth. This eternal life is a metaphor for intellectual accumulation. For instance, Adam collects old music instruments and Eve has a skill for telling the year they belong by touching these instruments by hand. Eve collects old books, which she carries as the only stuff in her travelling suitcase. They find these objects really precious, and this is a sign of their appreciation for genuine art. 
Adam is depressed for witnessing what "zombies" have done the earth. Criticizing human behavior against nature, as it is hard to find "good stuff" which is clean blood, he stresses that "zombies" "succeeded in contaminating their own blood, never mind their water". Here blood stands as a metaphor for human's harassment on their source of life; nature. A similar discussion occurs also at the end of the movie:

Adam: \%82 of human blood is water. Have the water wars started yet?

Or they are still with the oil?

Eve: Yes, they're just starting that.

Adam: They'll only figure out when it's too late.

Eve: How much of the human body is water?

Adam: 55 to $60 \%$

Eve: And how much the Earth surface?

Adam: Up 70\% is ocean and they're lakes and the rivers.

Eve's sister Eva, who came to visit them from L.A, is the complete opposite of Adam. Although she is a vampire and has all the gifts as an immortal, she is adapted to Zombies degenerated world. She chooses to live in a place where music, movies and every kind of art is industrialized. Adam's comment on L.A is “Zombie Central”. Eva's appetite for blood symbolizes the consumerist culture she lives in. While Adam and Eve drink very limited amount of blood, Eva always asks for more and she even drinks and kills Ian who is Adam's friend and nearly only connection with the outer world. After drinking Ian's blood, Eva feels sick. Adam's comment on this situation is "What did you expect? He is from the music industry".

\section{Discursive construction of the downfall of industrial capitalism}

Discursive construction of downfall of industrial capitalism in the movie has been done with iconography, settings, and salience discursive closures. 
Jarmusch aestheticizes the collapse of Detroit, by placing the city as a rebel zone for eco-sensitive vampires. Adam chooses to live right in the heart of the ruins remaining from the industrial capitalism. The city with evacuated houses, schools, factories and even churches offers him an opportunity to witness the collapse of the very thing he is against. Also it serves, as his wife states, a "wilderness" for him. So the downfall of the city is romanticized.

While Adam shows Eve the city he lives, Detroit, we see abandoned factories, as the symbol of collapse of industrial capitalism. Abandoned buildings, evacuated houses, dark streets functions as iconographic symbols and connate the downfall.

In the movie, the city is shown as desolate, there are very few people in the streets, and the nightclub protagonists visited was also relatively empty. Apparently, people left the city after the bankruptcy and this uncrowded setting contributes to the representation of downfall of Detroit.

Low-key lighting is dominant in the Detroit scenes of the movie; darkness serves as a salience discursive closure to give the depressed atmosphere, which is an outcome of downfall of the city.

Discursive construction of ecosocialist approach and its opposition to mass production, progress and growth obsession of industrial capitalism

Evaluation of the entire movie shows that the main stress of the narrative is on the destruction of the nature and genuine art, which is caused by senseless human kind and his/her misuse of technology.

Despite of the fact that Detroit's collapse has been a loss for American capitalism, Jarmusch finds hope in these ruins. Water, as a natural resource, not new models of industrial production, will be the locomotive of revival for the city. This approach pairs with ecosocialist understanding. 
As Kovel (2014, p. 17) puts out, ecosocialism is not only about criticizing industrial production of commodities but also against culture industry, which is conceptualized as "despiritualization". De-spiritualization is an essential problem in Jarmusch's movie as well; evidences of this can be seen in many different scenes, which have been stated above.

As mentioned previously in this article, Kovel (2014, p. 10) regards ecology as a connection between nature's elements, and humans are a part of it too. So there is also an existentialist crisis whenever one refers to an ecological crisis. Contamination of human blood, which is a result of industrial capitalism, evokes an existentialist disaster for humanity.

Kovel (2014, p. 10) warns that a dark age is very near for human kind, unless it resigns dominating and destructing nature for the sake of capital and production. Jarmusch shares this warning, as he desperately puts out that oil and water wars are up on human beings, and people will only understand what damage this would cause, only when it is too late.

\section{Conclusion}

The aim of this article was to read Jim Jarmusch's movie Only Lovers Left Alive on ecosocialist theory basis. Discourse analysis of the movie reveals that ecosocialist critic of industrial capitalism has parallel notions to the message that Jarmusch establishes.

The analogy can be seen in both ecological and cultural dimensions. As science, technology and genuine art became commodities under capitalist industrialization process, humanity has turned into a consumerist civilization, which consists of living deads.

This civilization lacks the awareness of the fact that this consuming and productivity obsession are destroying the natural resources, thus extinguishing the humankind. As humans are part of the nature, harming the nature will have similar results for humanity as well. 
That is why, for those who are aware of this course of action, collapse of the structures, which symbolize industrial capitalist system, such as Detroit city, serves as a place of hope where nature can reclaim its properties.

In the famous Chekov's gun example, if a gun is shown in a narrative, this means it is going to be discharged (Brooks, 2003, p. 76). Jim Jarmush disobeys this rule, as Adam's wooden bullet that he ordered to commit suicide, has never been discharged. As Eve -love of his life- arrives, Adam leaves the idea of death behind, because love is the only means of bearing this zombies world.

Love notion that is stressed in here, takes us to Rumi's teachings, which are referred implicitly in the movie. Rumi is the founder of Mevlevi order and his teachings are based on love, unity and Sufism. Jarmusch stated that whirling and spinning scenes in the movie are symbolizing Rumi’s philosophy (Atkinson, 2014).

Jarmusch shows that Adam chooses life over death with the help of his love. Rumi says, "Let yourself be drawn by the stronger pull of that which you truly love", that is, apparently, how lovers left alive.

*Antalya Akev University, Department of Communication Design

**Üsküdar University, Department of New Media and Journalism

\section{BIBLIOGRAPHY}

Alleva, R. (2014). Artful schlock, arty dreck. Commonweal, 141 (11), 24-25.

Anderson, M. E. (2012). Moving, writing, failing: Spatialities of ambivalence in Detroit's ruinscapes. Research in Drama Education: The journal of Applied Theatre and Performance, 17 (2). 193-208. 
Atkinson, N. (April 23, 2014). Interview with the vampire director: Jim Jarmusch on eternity and the fraud of Shakespeare in Only Lovers Left Alive. National Post. Retrieved from http://news.nationalpost.com

Benjamin, W. (2009). The work of art in the age of mechanical reproduction. New York: Classic Books America.

Betto, F. \& Löwy, M. (2010). Ecosocialism and spirituality. Capitalism Nature Socialism, 21 (2), 87-99.

Brooks, P. (2003). Inevitable discovery-law, narrative retrospectivity. Yale Journal of Law \& the Humanities, 15 (1), 71-102.

Eisenger, P. (2014). Is Detroit dead? Journal of Urban Affairs, 36 (1), 1-12.

Galster, G. (2015). A structural diagnosis and prescription for Detroit's fiscal crisis: Response to William Tabb's 'If Detroit is dead, some things need to be said at the funeral'. Journal of Urban Affairs, 37 (1), 17-20.

Kovel, J. (2007). The Enemy of Nature: The end of capitalism or the end of the world? Halifx: Fernwood Puplishing.

Kovel, J. (2014). Ecosocialism as a human phenomenon. Capitalism Nature Socialism, 25 (1), 1023. Doi: $10.1080 / 10455752.2013 .879800$

Löwy, M. (2015). Ecosocialism: A radical alternative to Capitalist Catastrophe. Chicago: Haymarket Books.

Machin, D. \& Mayr, A. (2012). How to do Critical Discourse Analysis: A multimodal introduction. London: Sage Publications.

McDonald, J. F. (2014). What happened to and in Detroit? Urban Studies, 51, 3309-3329.

Millington, N. (2010). Post-industrial imaginaries: nature, representation, and ruin in Detroit, Michigan (Unpublished master's thesis). University of Wisconsin, Wisconsin.

Nadine, C. (2000). Transforming poetry: The allegory of cultural studies. French Cultural Studies, 11 (32), 219-234. 
Phillips, G. C. (2014). Zombie cities: Urban form and population loss. Rutgers Journal of Law \& Public Policy, 11, 703-739.

O’Connor, J. (1998). Natural causes: Essays in ecological Marxism. New York: Guildford Press.

Schwartzman, D. (2009). Ecosocialism or Ecocatastrophe? Capitalism Nature Socialism, 20 (1), 6-33.

Slager, E. J. (2013). Touring Detroit: Ruins, representation and redevelopment (Unpublished master's thesis). University of Oregon Graduate School, Oregon.

Vultee, F. (2013). Finding porn in the ruin. Journal of Mass Media Ethics: Exploring Questions of Media Morality, 28 (2), 142-145. 